\title{
International Journal of Medical Science and Health Research
}

Vol. 5, No. 03; 2021

ISSN: 2581-3366

\section{Pneumothorax in Mechanically Ventilated Covid 19 Patients}

\author{
${ }^{1}$ BAYRAKÇI Onur, ${ }^{2}$ ALNIKIZIL Havva \\ ${ }^{1}$ Ersin Arslan Training and Research Hospital, Thoracic Surgery Department \\ ${ }^{2}$ Ersin Arslan Training and Research Hospital, Critical Care Department \\ Author \\ ALNIKIZIL Havva, Specialist MD \\ Ersin Arslan Training and Research Hospital, Critical Care Department Gaziantep TURKEY \\ Corresponding author \\ BAYRAKÇI Onur, Specialist MD \\ Ersin Arslan Training and Research Hospital, Thoracic Surgery Department \\ Adress:Eyüpoğlu neighborhood Hürriyet street Number 40, Gaziantep TURKEY \\ https://drersinarslaneah.saglik.gov.tr \\ Telephone: +903422210700 / 05059576924
}

doi: $10.51505 / \mathrm{ijmshr} .2021 .5302$

URL: http://dx.doi.org/10.51505/ijmshr.2021.5302

\begin{abstract}
Mechanical ventilator-associated pneumothorax is one of the most important undesirable fatal complications in intensive care. In our study 953 patients were retrospectively analyzed. 100 patients with positive Covid PCR test, with pneumonia and mechanical ventilation were included in the study in intensive care. $69 \%$ of the patients were male and $31 \%$ female. The mean age was 68.6 (range:33-92 median:69). Male gender, history of chronic disease, age $>65$ are associated with mortality. In Covid 19 pandemi period, an increase in the rates of pneumothorax associated with mechanical ventilation has been observed. The relationship between pneumothorax and mortality is known in the literature. Therefore, it is important to investigate the increase in pneumothorax rate and causes of death. Mechanical ventilator-associated pneumothorax was detected in 12 patients. Ppeak $>35 \mathrm{cmH} 2 \mathrm{O}$ is associated with both pneumothorax and mortality. Pneumothorax is associated with mortality. Interstitial diffuse pneumonia is associated with ARDS, pneumothorax and mortality separately. In our study, general pneumothorax has been found $1.4 \%(\mathrm{n}: 953)$ and mechanical ventilator related pneumothorax 4.1\%(n:288). Covid 19 is known to cause severe lung damage. It has been observed that especially patients with Covid 19 pneumonia interstitial involvement are much more susceptible to barotrauma.
\end{abstract}

Keywords: barotrauma, Covid 19, intensive care, mechanical ventilator-associated, pneumothorax.

\section{Introduction}

Pneumothorax is defined as lung collapse due to air accumulation between visceral and parietal pleura. Barotrauma incidence is stated as $0-50 \%$ in patients undergoing mechanical ventilation depending on the underlying disease, and general barotrauma is stated as $6.5 \%$ in acute 


\section{International Journal of Medical Science and Health Research}

Vol. 5, No. 03; 2021

ISSN: 2581-3366

respiratory distress syndrome(ARDS)[1-2]. Pneumothorax is seen in $84.2 \%$ of the patients with barotauma[3]. Due to its close relationship with mortality, pneumothorax secondary to the barotrauma in intensive care is one of the most important undesirable fatal complications. The relationship between pneumothorax and mortality is known in the literature. In Covid 19 pandemi period, an increase in the rates of pneumothorax associated with mechanical ventilation has been observed. It has been aimed to determine the frequency of pneumothorax, its relationship with ventilator parameters and causes of mortality in Covid 19 patients in intensive care.

\section{Materials \& Methods}

Our study was conducted in the Intensive Care Unit of Gaziantep Ersin Arslan Training and Research Hospital. Patients with a positive Covid-19 Polymerase Chain Reaction (PCR) test, typical viral pneumonia on computed tomography (CT) and in need of intensive care during hospital treatment were retrospectively examined (n:953). Among these patients, 100 patients who were intubated in the intensive care unit and provided invasive mechanical ventilation and died in the intensive care unit were included in the study. Electronic medical records and patient files of the patients were analyzed retrospectively. After the evaluation, demographic and clinical characteristics of the patients, ventilator parameters, radiological examinations, arterial blood parameters were collected. Berlin Criteria were used in the ARDS definition. Data of patients who developed pneumothorax were compared with other parameters. Statistically, groups were first evaluated using the Kolmogorov Smirnow Test. Statistical data were obtained by performing the analyzes in the Statistical Package for the Social Sciences(SPSS) program.

\section{Results}

After retrospective examinations, a total of 100 patients were included in the study.69\% of the patients were male and $31 \%$ female. The mean age was 68.6 (n:100 range:33-92 median:69).Mortality due to Covid-19 was more common in male gender ( $\mathrm{p}<0.0169 \%$ $\mathrm{n}: 69)$. When the relationship between age distribution and mortality was examined, the mortality rate was higher in patients over 65 years of age ( $p<0.01 \mathrm{n}: 67) .74$ patients had a history of chronic disease, 18 patients had no comorbidity, and medical history information was not available in 8 patients. A significant relationship was found between having a history of chronic disease and mortality ( $\mathrm{p}<0.01 \mathrm{n}$ : 74). Pneumothorax was detected in 14 patients, 12 of them mechanical ventilator-associated pneumothorax and 2 spontaneous pneumothorax(table 1).Pneumothorax rate $71 \%$ in men and $29 \%$ in women. There was no significant relationship with age. Chronic obstructive pulmonary disease(COPD) was seen in 6 patients with pneumothorax. A significant relationship was found between COPD and pneumothorax $(\mathrm{p}<0.01)$. Pneumothorax was seen on the right in 10 patients and on the left in 4 patients. Subcutaneous emphysema developed in 10 patients. Medical treatment was sufficient in 6 patients by adjusting the ventilator settings (decreasing $\mathrm{Pp}$, ventilator mood change, increasing frequency). However, surgical treatment (tube thoracostomy) were performed in 8 patients. Two patients were treated with a thoracic tube, and the tube thoracostomy could be terminated, while the thorax tube of the 


\section{International Journal of Medical Science and Health Research}

Vol. 5, No. 03; 2021

ISSN: 2581-3366

other 6 patients could not be removed due to continued air leakage. 12 patients with mechanical ventilator-associated pneumothorax; 2 died within the first 24 hours after pneumothorax was detected, and 5 within the first 48 hours. A significant relationship was found between pneumothorax and mortality( $<<0.0112 \% \mathrm{n}$ :12).It was observed that pressure-controlled mode was preferred for 2 patients and volume-controlled mode was preferred for 10 patients as the mechanical ventilator mode. A significant relationship was found between Positive End Expiratory Pressure(PEEP) $>8 \mathrm{cmH} 2 \mathrm{O}$ with mortality(p $<0.05 \mathrm{n}: 40)$, but there was no statistically significant relationship between pneumothorax with $\operatorname{PEEP}(\mathrm{p}: 0.47 \mathrm{n}: 40) . P p>35$ $\mathrm{cmH} 2 \mathrm{O}$ was found to be associated with both mortality and pneumothorax (p: $0.001 \mathrm{n}: 16$, figure 1).ARDS was detected in 33 of the patients and it was found to be associated with both pneumothorax and mortality ( $\mathrm{p}<0.05$, figure 2 ). Whether ARDS or not, blood gas results were found to be associated with $\mathrm{PaO} 2 / \mathrm{FiO} 2<100$ mortality ( $<<0.01 \mathrm{n}$ : 62). There was an appearance compatible with interstitial pneumonia in the first $\mathrm{CT}$ of the patients who developed ARDS. Interstitial diffuse pneumonia in CT is associated with ARDS, pneumothorax and mortality separately ( $\mathrm{p}<0.05 \mathrm{n}: 31$, figure 3 ). There was no significant relationship between tidal volume, $\mathrm{PaO} 2$ and $\mathrm{PCO} 2$ levels and pneumothorax and mortality (table 2).In our study, general pneumothorax has been found $1.4 \%(\mathrm{n}: 953)$ and mechanical ventilator related pneumothorax $4.1 \%(\mathrm{n}: 288)$.

\section{Discussion}

In humans, normal breathing occurs with negative intra-thoracic pressure. However, patients who need a mechanical ventilator for reasons such as respiratory failure are ventilated by the respiratory device with positive pressure. Naturally, positive pressure ventilation is not physiological and causes complications such as alveolar barotrauma[4].

Barotrauma is usually caused by alveolar damage. Air passes through the damaged alveoli to many different places. In this case, complications such as pneumothorax, pneumomediastinum and subcutaneous emphysema are seen when there is excessive air passage [5]. Certain diseases, including COPD, asthma, and ARDS, can predispose a person to pulmonary barotrauma. These diseases are related to dynamic hyperinflation or poor lung compliance. Therefore, sensitivity to barotrauma occurs after increased alveolar pressure [6].In our study, pneumothorax and subcutaneous emphysema were observed more frequently in patients with COPD, ARDS and diffuse interstitial pneumonia. The pressure created by the air in the alveoli at the end of expiration is known as auto-PEEP. Occasionally, auto-PEEP can cause ventilator incompatibility, increased tension of the alveoli and consequently barotraumas [7].In the analysis of our study, PEEP value> 8 was not found to be associated with pneumothorax. However, it was found statistically that it was associated with mortality. Plateau pressure; It is the pressure measured after inspiration and before expiration begins. Inspiratory pressure (IP); It is the pressure that continues through the insprium and largely creates the tidal volume.Peak pressure is; It is the highest pressure recorded during the insprium. Practically Peak pressure is equal to the sum of IP and PEEP. It has been reported that $\mathrm{Pp}>50 \mathrm{cmH} 2 \mathrm{O}$ causes alveolar damage during mechanical 


\section{International Journal of Medical Science and Health Research}

Vol. 5, No. 03; 2021

ISSN: 2581-3366

ventilation [8].In addition, pneumothorax if there is a high PEEP value It has been shown to be a risk factor in terms of [9].In another study, it is recommended not to exceed Pp 40-45 cmH2O due to barotraumas [10].In our study, on the other hand, no significant relationship was found between pneumothorax and PEEP. Although the PEEP value was 8, ventilator-associated pneumothorax was detected in 2 patients even at 32 and 33 Pp values. Statistically, when the Pp value is above 35 , a significant relationship with pneumothorax has been detected. For this reason, it is recommended to have a Pp value below 35 in the mechanical ventilator in covid 19 pneumonia. This is thought to be due to severe damage to the lung, interstitial involvement, fibrosis, and decreased lung compliance, and increased airway resistance. Pneumothorax due to barotrauma; It is in the category of traumatic pneumothorax. In blunt thoracic trauma, $6.7 \%$ pneumothorax is seen without rib fracture [11].Pneumothorax due to barotauma is very rare in patients who are mechanically ventilated in the intensive care unit[12]. However, it was observed that this rate increased significantly during the Covid 19 pandemic period. In our study; Covid 19 intensive care mechanical ventilator-associated pneumothorax rate is $12 \%$. Oxygen support and close observation are applied in pneumothorax below $20 \%$ in our clinical experience. Although there is pneumothorax due to mechanical ventilator; Tube thoracostomy was not performed in 6 patients with pneumothorax less than $20 \%$. Close observation was taken by lowering Pp in the mechanical ventilator, changing the mood, increasing the respiratory frequency, and the medical approach was sufficient. However, the other 8 pneumothorax patients required a surgical method and underwent tube thoracostomy. Tube thoracostomy could be terminated by completing the treatment of only 2 pneumothorax patients (both spontaneous pneumothorax). The other 6 patients who underwent tube thoracostomy and received ventilator support; could not be terminated due to continued air leak.

\section{Conclusions}

Mechanical ventilator-associated pneumothorax is one of the most important undesirable fatal complications in intensive care. Covid 19 is known to cause severe lung damage. It has been observed that especially patients with Covid 19 pneumonia interstitial involvement are much more susceptible to barotrauma. Therefore, it is recommended to have PEEP $<9 \mathrm{cmH} 2 \mathrm{O}$ and $\mathrm{P}$ peak $<35 \mathrm{cmH} 2 \mathrm{O}$ in terms of ventilation. Chest radiography as often as possible in patients receiving mechanical ventilator support may help to detect possible pneumothorax early. Since it is known to infect Covid 19 with the respiratory tract; If the patient has a tube thoracostomy, special attention should be paid to its isolation.

\section{Conflict of interest}

All authors declared that there is no conflict of interest.

\section{Ethical Approval}

Republic of Turkey Ministry of Health, 2020/12-10T13_04_00 numbered and Gaziantep University Medical Ethics Committee 2021/16 numbered approval have been received. 


\section{International Journal of Medical Science and Health Research}

Vol. 5, No. 03; 2021

ISSN: 2581-3366

\section{References}

1.Diaz R, Heller D: Barotrauma and mechanical ventilation. StatPearls Publishing, Treasure Island; 2020.

2.Anzueto A, Frutos-Vivar F, Esteban A, et al.: Incidence, risk factors and outcome of barotrauma in mechanically ventilated patients. Intensive Care Med. 2004, 30:612619. 10.1007/s00134-004-2187-7

3.Elmas Uysal F, Korkmaz Ekren P, Kuntman A, et al. Barotrauma Associated with Mechanical Ventilation. Yoğun Bakım Derg 2017; 8: 39-43.

4.Boussarsar M, Thierry G, Jaber S, Roudot-Thoraval F, Lemaire F, Brochard L. Relationship between ventilatory settings and barotrauma in the acute respiratory distress syndrome. Intensive Care Med. 2002 Apr;28(4):406-13.

5.Eisner MD, Thompson BT, Schoenfeld D, Anzueto A, Matthay MA., Acute Respiratory Distress Syndrome Network. Airway pressures and early barotrauma in patients with acute lung injury and acute respiratory distress syndrome. Am J Respir Crit Care Med. 2002 Apr 01;165(7):978-82.

6.Anzueto A, Frutos-Vivar F, Esteban A, Alía I, Brochard L, Stewart T, Benito S, Tobin MJ, Elizalde J, Palizas F, David CM, Pimentel J, González M, Soto L, D'Empaire G, Pelosi P. Incidence, risk factors and outcome of barotrauma in mechanically ventilated patients. Intensive Care Med. 2004 Apr;30(4):612-9.

7.Mughal MM, Culver DA, Minai OA, Arroliga AC. Auto-positive end-expiratory pressure: mechanisms and treatment. Cleve Clin J Med. 2005 Sep;72(9):801-9.

8.Petersen GW, Baier H. Incidence of pulmonary barotrauma in a medical ICU. Crit Care Med 1983; 11: 67-9.

9.Gammon RB, Shin MS, Buchalter SE. Pulmonary barotrauma in mechanical ventilation. Patterns and risk factors. Chest 1992; 102: 568-72.

10. Nieman GF, Satalin J, Andrews P, Aiash H, Habashi NM, Gatto LA. Personalizing mechanical ventilation according to physiologic parameters to stabilize alveoli and minimize ventilator induced lung injury (VILI). Intensive Care Med Exp 2017;5:8.

11.Liman ST, Kuzucu A, Tastepe AI, Ulasan GN, Topcu S. Chest injury due to blunt trauma. Eur J Cardiothorac Surg 2003 Mar;23(3):374-8.

12. Cullen DJ, Caldera DL. The incidence of ventilation-induced pulmonary barotraumas in critically ill patients. Anesthesiology 1979;50:185-90. 
International Journal of Medical Science and Health Research

Vol. 5, No. 03; 2021

ISSN: 2581-3366

Tables and Figures

\begin{tabular}{|l|l|l|l|l|l|}
\cline { 2 - 6 } \multicolumn{1}{c|}{} & Gender & Age & Chronic disease & Pneumonia type & Pneumothorax type \\
\hline $\mathbf{1}$ & Male & 66 & Diabetes mellitus & Interstitial pneumonia & MVA \\
\hline $\mathbf{2}$ & Male & 61 & COPD & Interstitial pneumonia & MVA \\
\hline $\mathbf{3}$ & Male & 70 & COPD & Lobular pneumonia & MVA \\
\hline $\mathbf{4}$ & Female & 76 & COPD & Interstitial pneumonia & MVA \\
\hline $\mathbf{5}$ & Male & 71 & COPD & Interstitial pneumonia & MVA \\
\hline $\mathbf{6}$ & Female & 84 & COPD & Interstitial pneumonia & MVA \\
\hline $\mathbf{7}$ & Male & 65 & No disease & Interstitial pneumonia & Spontaneous \\
\hline $\mathbf{8}$ & Male & 33 & No disease & Unknown & MVA \\
\hline $\mathbf{9}$ & Male & 71 & COPD & Interstitial pneumonia & MVA \\
\hline $\mathbf{1 0}$ & Female & 92 & Obesity & Interstitial pneumonia & MVA \\
\hline $\mathbf{1 1}$ & Male & 63 & Coronary artery disease & Interstitial pneumonia & Spontaneous \\
\hline $\mathbf{1 2}$ & Female & 53 & No disease & Lobular pneumonia & MVA \\
\hline $\mathbf{1 3}$ & Male & 54 & No disease & Lobar pneumonia & MVA \\
\hline $\mathbf{1 4}$ & Male & 79 & Hypertension & Lobar pneumonia & MVA \\
\hline
\end{tabular}

Table 1: Characteristics of pneumothorax patients

*COPD: Chronic obstructive pulmonary disease MVA: Mechanical ventilator associated

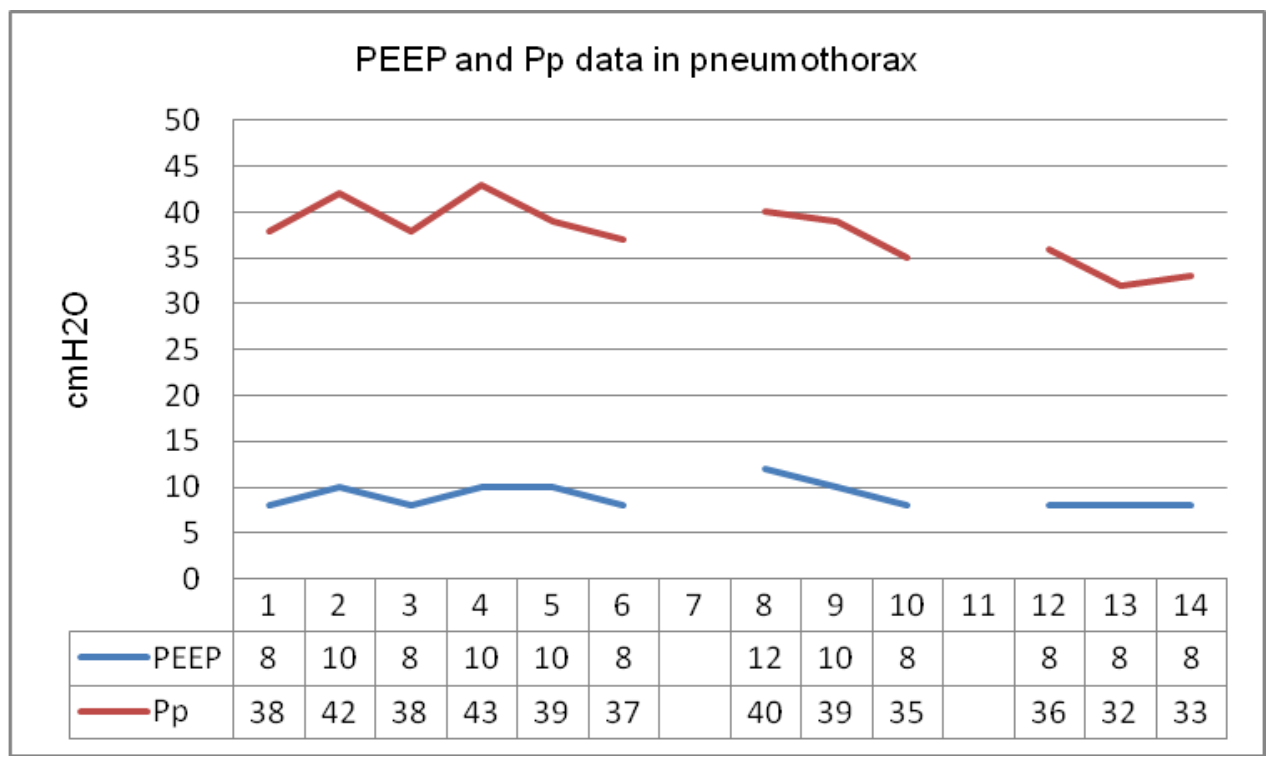

Figure 1: PEEP and Pp data in pneumothorax

*PEEP: Positive End Expiratory Pressure Pp: peak pressure

*Patients 7 and 11 spontaneous pneumothorax,

others mechanical ventilator-associated pneumothorax 
International Journal of Medical Science and Health Research

Vol. 5, No. 03; 2021

ISSN: 2581-3366

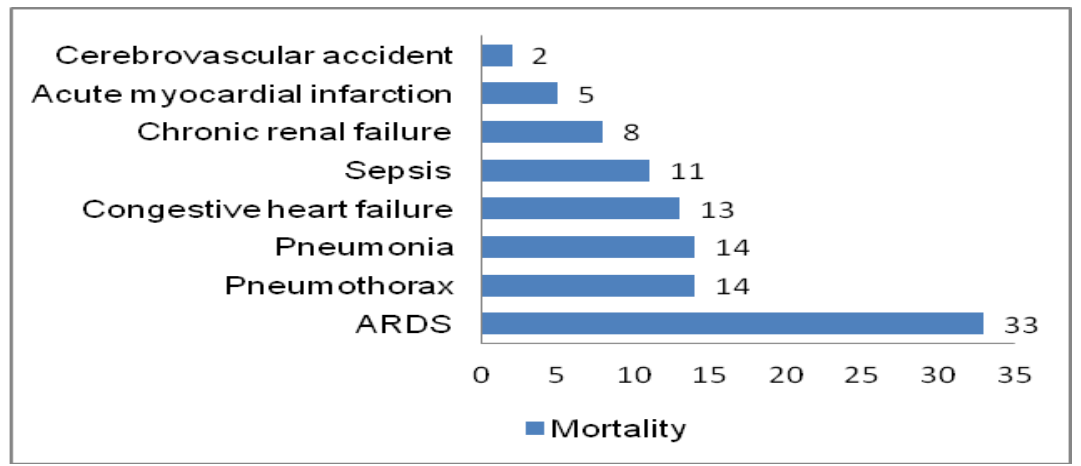

Figure 2: Mortality distribution

ARDS: Acute respiratory distress syndrome

\begin{tabular}{|l|l|l|l|}
\hline Parameters & $\mathrm{n}$ & Pneumothorax $(\mathrm{p})$ & Mortality $(\mathrm{p})$ \\
\hline Male & 69 & 0.052 & $<0.01$ \\
\hline Female & 31 & 0.30 & 0.08 \\
\hline$>65$ age & 67 & 0.06 & $<0.01$ \\
\hline PEEP $>8 \mathrm{cmH} 2 \mathrm{O}$ & 84 & 0.06 & $<0.01$ \\
\hline Ppeak $>35 \mathrm{cmH} 2 \mathrm{O}$ & 50 & $<0.01$ & $<0.01$ \\
\hline PaO2 / FiO2 $<100$ & 83 & $<0.01$ & $<0.01$ \\
\hline Interstitial pneumonia & 68 & $<0.01$ & $<0.01$ \\
\hline Comorbidity & 72 & $<0.01$ & $<0.01$ \\
\hline COPD & 14 & $<0.05$ & $<0.01$ \\
\hline ARDS & 33 & 0.06 & $<0.01$ \\
\hline
\end{tabular}

Table 2: Statistical analysis of parameters with pneumothorax and mortality

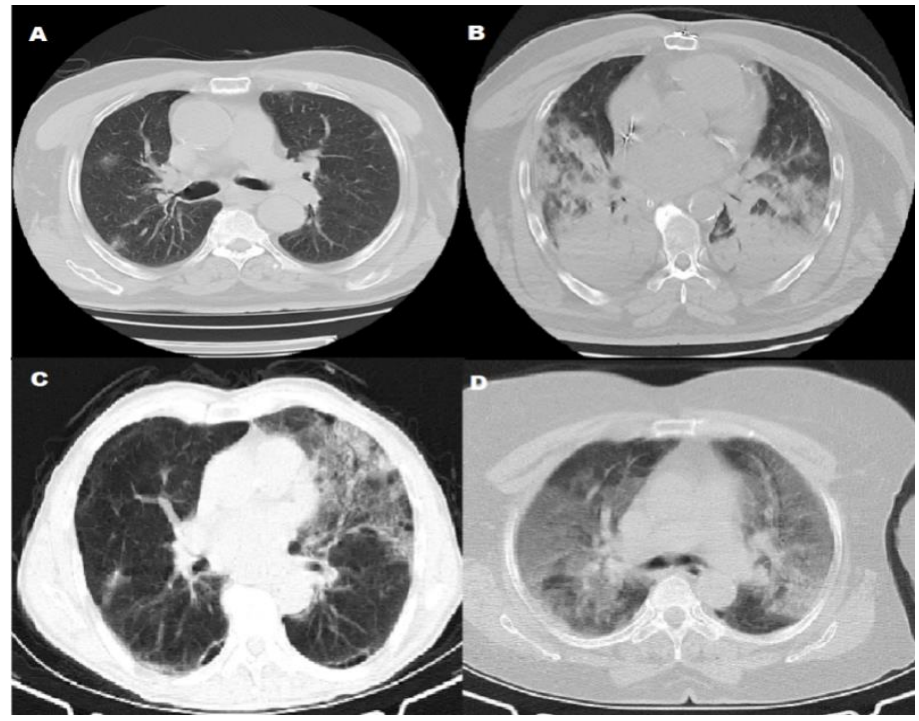

Figure 3: Pneumonia types in Covid 19

A.Lobular B.Lobar C.Interstitial D.Common Interstitial 